\title{
Thermodynamic modeling to analyse composition of carbonaceous coatings of MnO and other oxides of manganese grown by MOCVD
}

\author{
SUKANYA DHAR ${ }^{\dagger}$, A VARADE and S A SHIVASHANKAR* \\ Materials Research Centre, Indian Institute of Science, Bangalore 560 012, India \\ ${ }^{\dagger}$ Mechanical Engineering Department, Reva Institute of Technology and Management, Bangalore 560 064, India
}

MS received 18 November 2009

\begin{abstract}
Equilibrium thermodynamic analysis has been applied to the low-pressure MOCVD process using manganese acetylacetonate as the precursor. "CVD phase stability diagrams" have been constructed separately for the processes carried out in argon and oxygen ambient, depicting the compositions of the resulting films as functions of CVD parameters. For the process conduced in argon ambient, the analysis predicts the simultaneous deposition of $\mathrm{MnO}$ and elemental carbon in 1:3 molar proportion, over a range of temperatures. The analysis predicts also that, if CVD is carried out in oxygen ambient, even a very low flow of oxygen leads to the complete absence of carbon in the film deposited oxygen, with greater oxygen flow resulting in the simultaneous deposition of two different manganese oxides under certain conditions. The results of thermodynamic modeling have been verified quantitatively for lowpressure CVD conducted in argon ambient. Indeed, the large excess of carbon in the deposit is found to constitute a $\mathrm{MnO} / \mathrm{C}$ nanocomposite, the associated cauliflower-like morphology making it a promising candidate for electrode material in supercapacitors. CVD carried out in oxygen flow, under specific conditions, leads to the deposition of more than one manganese oxide, as expected from thermodynamic analysis (and forming an oxide-oxide nanocomposite). These results together demonstrate that thermodynamic analysis of the MOCVD process can be employed to synthesize thin films in a predictive manner, thus avoiding the inefficient trial-and-error method usually associated with MOCVD process development. The prospect of developing thin films of novel compositions and characteristics in a predictive manner, through the appropriate choice of CVD precursors and process conditions, emerges from the present work.
\end{abstract}

Keywords. MOCVD; manganese oxide; carbon matrix; thermodynamic analysis; phase stability diagram.

\section{Introduction}

Metalorganic chemical vapour deposition (MOCVD) and organometallic vapour phase epitaxy (OMVPE) have been shown to be versatile techniques for the preparation of thin films, coatings, and epitaxial layers of a variety of materials, including oxides, nitrides, and compound semiconductors (Vossen and Kern 1991). The chemical precursors for these film deposition processes contain carbon, whether they are metalorganic complexes (where no direct metal-carbon bond is present), or organometallics (in which the metal is bound directly to carbon). One of the natural consequences of using carbon-containing CVD precursors is that the resulting film may contain carbon. In many applications, such as in the fabrication of semiconductor devices, the presence of carbon in the deposit is usually undesirable. For example, vapour phase epitaxy is a preferred process for the epitaxial growth of III-V semiconductors, such as GaAs (Stringfellow 1989).

If carbon is present in a film or a coating as a result of the chemical precursor(s) containing carbon in the molecu-

\footnotetext{
*Author for correspondence (shivu@ mrc.iisc.ernet.in)
}

lar structure, it may be in the form of carbides, carbonates, more complex carbonaceous compounds, or in the form of elemental carbon. The presence of elemental carbon in a film or a coating need not always be undesirable. Specifically, it may be noted here that composites of a metal oxide and carbon have been investigated extensively in recent years for application as electrode materials in supercapacitors, and that these composites are usually made by physical mixing of the metal oxide and carbon for $\mathrm{RuO}_{2}$ and $\mathrm{MnO}_{2}$ (Zheng and Jow 1995; Lee and Goodenough 1999; Lee et al 2001; Pang et al 2000; Jeong and Manthiram 2002; Kim and Popov 2002; Jang et al 2003, 2006; Park et al 2003). The integration of carbon into other materials can enhance various mechanical, electrical and chemical properties (Devi et al 2002; Singh et al 2002). Furthermore, the deliberate inclusion of carbon in an oxide film can be regarded as leading to the formation of a composite thin film, possessing desirable characteristics that stem from its composite nature. Varade et al (2009) have carried out thermal CVD in argon ambient using manganese acetylacetonate as the precursor leading to a dark, conductive coating on stainless steel substrates at a temperature of about $650^{\circ} \mathrm{C}$. Such coatings are found to be comprising of 
nanostructured $\mathrm{MnO}$ in a matrix of graphitic carbon, both of which are deposited simultaneously from the precursor, constituting a nanocomposite. The carbon matrix is expected to restrict the growth of the oxide, providing a nanostructured morphology to the film. The cauliflower-like microstructure (observed by electron microscopy) of the coating leads to a large specific surface area (as measured by the BrunauerEmmett-Teller technique), making it a candidate material for electrode material in supercapacitors.

Thus, if the MOCVD process can be engineered in such a way as to lead to the incorporation of carbon into a thin film or a coating, interesting and useful materials may be formed. An additional possibility is that the carbon content (in elemental form) of a coating may be amenable to control through the manipulation of the various CVD process parameters. In particular, the carbon content of the precursor molecule may itself be varied in an attempt to engineer the extent of carbon incorporation in the resulting deposit. Such a deliberate inclusion may be assured by choosing CVD conditions not empirically, but through a thermodynamic modeling of the process.

Equilibrium thermodynamics has been applied successfully to understand the growth of epitaxial layers of alloy semiconductors such as $\mathrm{Ga}_{1-x} \mathrm{Al}_{x}$ As (Stringfellow 1989), or BN on graphite substrate (Huang et al 1999). Sarin (1995) has demonstrated that partial or complete coupling of modeling, based on fundamental principles related to equilibrium thermodynamics and process kinetics, and the corresponding experimentations, can be effectively used systematically to develop customized CVD coatings. Thermodynamic modeling has also been employed to analyse the MOCVD process for thin films of $\mathrm{RuO}_{2}$ (Kang et al 2000), $\mathrm{Cu}$ (Mukhopadhyay et al 2002a, b), $\mathrm{ZrO}_{2}$ (Baum and Larson 1993; Fredriksson and Forsgren 1995; Dhar et al 2008a) and iron oxides (Dhar et al 2008b). Such analysis computes the compositions of the thin films and the gaseous products as functions of parameters such as temperature, pressure, and partial pressure of various gases. This leads to construction of "MOCVD phase stability diagrams" which help in selecting the ranges of the process parameters to obtain films of particular compositions experimentally.

With this view, we have investigated the MOCVD of manganese oxide(s) with manganese(II) acetylacetonate [Mn $(\text { acac })_{2}\left(\mathrm{H}_{2} \mathrm{O}\right)_{2}$ or diaquobisacetylacetonatomanganese(II)] as precursor, using equilibrium thermodynamic analysis of the process, to obtain the composition of the films as functions of CVD parameters, both in argon and oxygen ambient. Specifically, the nature of the carbon-rich composite manganese oxide coating formed, when oxygen gas is deliberately not injected into the CVD chamber, has been examined. A phase stability diagram is constructed for oxygen atmosphere, predicting the stability windows for deposition of different oxides over different ranges of thermodynamic variables. For experimental validation, various films are grown under argon and oxygen atmosphere at different substrate temperatures $\left(T_{\text {sub }}\right)$, total reactor pressure $(P)$, and at various flow rates of oxygen $\left(F_{\text {oxy }}\right)$. The resulting films are characterized by Raman spectroscopy and X-ray diffraction (XRD) for phase identification, X-ray photoelectron spectroscopy (XPS) using $\mathrm{Al}-\mathrm{K}_{\alpha}$ radiation for quantitative compositional analysis, and scanning electron microscopy (SEM) for morphological studies.

\section{Procedure}

\subsection{Thermodynamic analysis}

The method of equilibrium calculations is based on the minimization of the Gibbs free energy of the system under consideration, satisfying the mass balance conditions (Eriksson 1971). Application of this approach to a MOCVD process requires the identification of all the possible reactants and reaction products.

The schematic molecular structure of the complex is given in figure 1(a). The TG/DTA data (inset of figure 1(a)) of

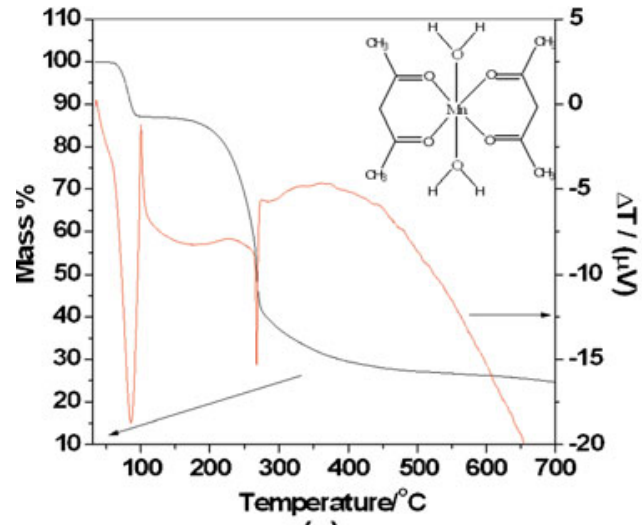

(a)

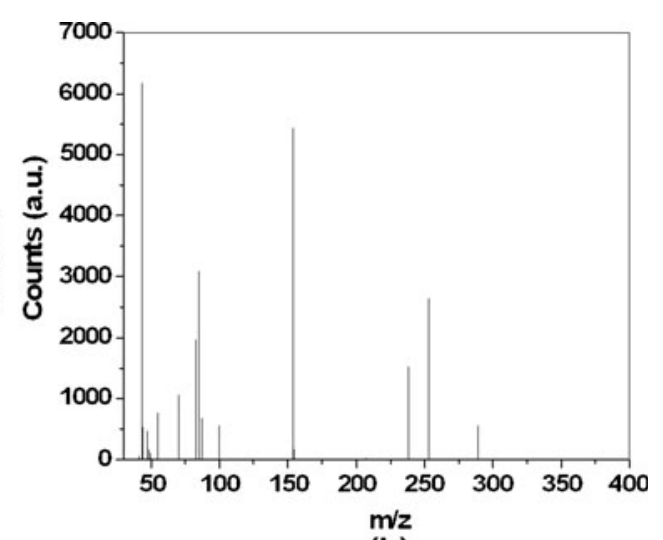

(b)

Figure 1. (a) Simultaneous TG/DTA of the precursor complex $\mathrm{Mn}(a c a c)_{2}\left(\mathrm{H}_{2} \mathrm{O}\right)_{2}$, with the molecular structure in the inset and (b) electron impact mass spectrum of the complex. 
the complex indicate that, when $\mathrm{Mn}(\text { acac })_{2}\left(\mathrm{H}_{2} \mathrm{O}\right)_{2}$, a subliming solid, is heated, molecules of the water of crystallization are first detached. In an actual CVD process, these $\mathrm{H}_{2} \mathrm{O}$ molecules are transported through the reaction chamber during the stage of preliminary to actual film deposition, and pumped out. Thus, film deposition involves vapourization from the dehydrated complex. Therefore, only the decomposition products of dehydrated $\operatorname{Mn}(a c a c)_{2}$ need be considered in the thermodynamic calculations. Every possible solid product formed with $\mathrm{Mn}, \mathrm{C}, \mathrm{H}$, and $\mathrm{O}$ was considered for the analytical study, along with the possible gaseous products (table 1). The procedure for enumerating the gaseous species to be considered in the calculations, involving consultation of the mass spectrum of the precursor and employing "chemical reasoning", is described in our earlier publications (Mukhopadhyay et al 2002a, b; Dhar et al 2008a, b) for metalorganic complexes with different ligands. The procedure for enumerating the gaseous species possibly produced from $\operatorname{Mn}(a c a c)_{2}$ is explained below.

Mass spectral analysis deals with ions obtained from electron impact, and in no way simulates conditions in a thermal CVD process. Nevertheless, we have used mass analysis as a preliminary measure to infer the decomposition products, as such an approach leads successfully to "CVD phase stability diagrams" supported by experiment (Mukhopadhyay et al 2002a). From the mass spectrum (figure 1(b)) of the precursor complex, $\mathrm{Mn}(a c a c)_{2}\left(\mathrm{H}_{2} \mathrm{O}\right)_{2}(\mathrm{~m} / \mathrm{z}=289)$, it is evident that the water of crystallization is detached from the molecule to produce $\operatorname{Mn}(a c a c)_{2}(m / z=253)$, which reduces further to $\operatorname{Mn}(a c a c)_{1}(\mathrm{~m} / \mathrm{z}=154)$, and the 'acac' $(\mathrm{m} / \mathrm{z}=$ 100) fragments. In the list of the gaseous species present in the chamber, fragments with higher molecular weights were not included, as they are expected to undergo further fragmentation to produce $\mathrm{CHCO}(\mathrm{m} / \mathrm{z}=41), \mathrm{CH}_{3} \mathrm{CO}(\mathrm{m} / \mathrm{z}=$ 43), $\mathrm{CO}$, the $\mathrm{CH}_{3}$-radical etc. The first two fragments are expected to decompose further to produce the $\mathrm{CH}_{3}$-group, $\mathrm{CO}$, carbon and hydrogen gas. Other possibility may be the formation of $\mathrm{C}_{2} \mathrm{H}_{2} \mathrm{O}$ (ketene), and $\mathrm{CH}_{3} \mathrm{CHO}$ (acetaldehyde). The $m / z$ value for $\mathrm{CO}(28)$ and the $\mathrm{CH}_{3}$-group (15) are too low to be detected by mass spectral analysis employed in the present study, but several peaks such as those with $\mathrm{m} / \mathrm{z}=$ 238,139 , and 85 , which may be obtained when a $\mathrm{CH}_{3}$ group is detached from $\operatorname{Mn}(a c a c)_{2}, \operatorname{Mn}(a c a c)_{1}$, and the 'acac' fragment, respectively are observed clearly in the spectrum.
Thus, in the case of a process conducted in the absence of a reactive gas (such as oxygen), i.e. for a process conducted in an inert ambient such as that of argon, the gaseous products used for the present analytical study are $\mathrm{CO}, \mathrm{H}_{2}, \mathrm{C}_{2} \mathrm{H}_{6}$ (obtained from the unstable methyl radical), $\mathrm{C}_{2} \mathrm{H}_{2} \mathrm{O}$ (ketene), and $\mathrm{CH}_{3} \mathrm{CHO}$ (acetaldehyde).

If the CVD process is conducted in oxygen ambient, the product gaseous species inferred by consulting the mass spectrum are expected to be partially or fully oxidized. $\mathrm{CO}_{2}$ and water vapour are expected from the total or partial oxidation of the hydrocarbons. $\mathrm{CO}_{2}$ is also expected from carbon and CO. Different organic acids are expected from acetaldehyde and ketene. Thus, gaseous products used for the thermodynamic analysis of a CVD process conducted in oxygen ambient are $\mathrm{CO}, \mathrm{CO}_{2}, \mathrm{H}_{2} \mathrm{O}, \mathrm{C}_{2} \mathrm{H}_{6}, \mathrm{C}_{2} \mathrm{H}_{2} \mathrm{O}, \mathrm{CH}_{3} \mathrm{CHO}$, $\mathrm{HCOOH}$ (formic acid), and $\mathrm{CH}_{3} \mathrm{COOH}$ (acetic acid).

Calculations were performed, as described earlier (Mukhopadhyay et al 2002a, b; Dhar et al 2008a, b), to deduce the concentrations of the various solid and gaseous phases formed when the substrate temperature $\left(T_{\text {sub }}\right)$ and total reactor pressure $(P)$ are varied in inert (argon) atmosphere, and also as a function of the molar ratio of flow rates of oxygen and precursor vapour $\left(F_{\text {oxy }} / F_{\text {pre }}\right)$ in oxygen ambient. A commercially available PC-based software programme was used for these calculations [Autokumpu HSC Chemistry 3.1, Finland]. The corresponding phase stability diagrams were also constructed.

\subsection{Experimental deposition}

Depositions were carried out under different CVD conditions in a home made low-pressure reactor described elsewhere (Mane and Shivashankar 2003), using $\mathrm{Mn}(\text { acac })_{2}\left(\mathrm{H}_{2} \mathrm{O}\right)_{2}$ as the precursor. The range of CVD conditions employed is listed in table 2. The manganese complex, which is a crystalline solid at room temperature, was synthesized and purified in house. Thermogravimetric analysis shows that the manganese complex begins to sublime at about $200^{\circ} \mathrm{C}$. High purity gases were used in the CVD process: argon as the carrier gas, and oxygen as the reactant, their flow regulated by electronic mass flow controllers. The recorded oxygen flow rate was translated to a molar flow rate $\left(F_{\text {oxy }}\right)$. The molar flow rate of the manganese precursor $\left(F_{\text {pre }}\right)$ was

Table 1. Conditions used for MOCVD.

Precursor used
Deposition temperature
Reactor pressure
Precursor vaporizer temperature
Carrier gas $(\mathrm{Ar})$ flow
Reactive gas $\left(\mathrm{O}_{2}\right)$ flow
Deposition time
Substrates used

Precursor used

Deposition temperature

Reactor pressure

Precursor vaporizer temperature

Carrier gas (Ar) flow

Deposition time

Substrates used 
Table 2. Trial list for $\operatorname{Mn}(\text { acac })_{2}\left(\mathrm{H}_{2} \mathrm{O}\right)_{2}$ for equilibrium calculation.

\begin{tabular}{|c|c|c|}
\hline Precursor & Condition & List of chemical species \\
\hline $\mathrm{Mn}(a c a c)_{2}\left(\mathrm{H}_{2} \mathrm{O}\right)_{2}$ & Without oxygen & $\begin{array}{c}\text { Solid: } \mathrm{Mn}, \mathrm{Mn} \text {-oxides }\left(\mathrm{MnO}, \mathrm{Mn}_{3} \mathrm{O}_{4}, \mathrm{Mn}_{2} \mathrm{O}_{3}, \mathrm{MnO}_{2}\right), \mathrm{Mn}(\mathrm{OH})_{2} \\
\text { Mn-carbides }\left(\mathrm{MnC}_{2}, \mathrm{Mn}_{3} \mathrm{C}, \mathrm{Mn}_{7} \mathrm{C}_{3}, \mathrm{Mn}_{15} \mathrm{C}_{4}, \mathrm{Mn}_{23} \mathrm{C}_{6}\right), \mathrm{MnCO}_{3}, \mathrm{C} \\
\text { Gas: } \mathrm{CO}, \mathrm{H}_{2}, \mathrm{C}_{2} \mathrm{H}_{6} \text { (obtained from the unstable methyl radical), } \\
\mathrm{C}_{2} \mathrm{H}_{2} \mathrm{O} \text { (ketene), and } \mathrm{CH}_{3} \mathrm{CHO} \text { (acetaldehyde) }\end{array}$ \\
\hline $\mathrm{Mn}(a c a c)_{2}\left(\mathrm{H}_{2} \mathrm{O}\right)_{2}$ & With oxygen & $\begin{array}{l}\text { Solid: } \mathrm{Mn}, \mathrm{Mn} \text {-oxides }\left(\mathrm{MnO}, \mathrm{Mn}_{3} \mathrm{O}_{4}, \mathrm{Mn}_{2} \mathrm{O}_{3}, \mathrm{MnO}_{2}\right), \mathrm{Mn}(\mathrm{OH})_{2}, \\
\text { Mn-carbides }\left(\mathrm{MnC}_{2}, \mathrm{Mn}_{3} \mathrm{C}, \mathrm{Mn}_{7} \mathrm{C}_{3}, \mathrm{Mn}_{15} \mathrm{C}_{4}, \mathrm{Mn}_{23} \mathrm{C}_{6}\right), \mathrm{MnCO}_{3}, \mathrm{C} \\
\text { Gas: } \mathrm{CO}, \mathrm{CO}_{2}, \mathrm{H}_{2} \mathrm{O}, \mathrm{C}_{2} \mathrm{H}_{6}, \mathrm{C}_{2} \mathrm{H}_{2} \mathrm{O}, \mathrm{CH}_{3} \mathrm{CHO}, \mathrm{HCOOH}, \mathrm{CH}_{3} \mathrm{COOH}\end{array}$ \\
\hline
\end{tabular}

deduced from the average rate of mass loss of the precursor during the course of a CVD run lasting up to $90 \mathrm{~min}$. Many depositions were carried out in the ambient of argon only, the carrier gas. Depositions were obtained on different substrates, i.e. $\mathrm{Si}(100)$, ceramic $\mathrm{Al}_{2} \mathrm{O}_{3}$, and stainless steel, which were often placed in the chamber adjacent to one another, to ensure that deposition occurred on different surfaces under the same CVD conditions. However, many of the detailed investigations were carried out on coatings prepared on stainless steel (SS 316) substrates. The average thickness of the coatings was determined from the mass gained by the substrate due to the coating, as measured by a semimicrobalance $(10 \mu \mathrm{g}$ resolution). The resulting films were characterized by Raman spectroscopy and X-ray diffraction (XRD) for phase identification, X-ray photoelectron spectroscopy (XPS) using Al- $\mathrm{K}_{\alpha}$ radiation for quantitative compositional analysis, and scanning electron microscopy (SEM) for morphological studies.

\section{Results and discussion}

\subsection{Thermodynamic analysis}

3.1a In argon ambient: In this part of the study, we concentrate on that range of CVD parameters, which lead to the simultaneous deposition of the monovalent oxide of manganese $(\mathrm{MnO})$ and carbon. Such simultaneous deposition is presumably due to the reaction pathway that is specific to the low-pressure argon ambient at elevated temperature of the substrate, wherein $\mathrm{MnO}$ and $\mathrm{C}$ are the two solid products. Such a solid deposit of $\mathrm{MnO}$ and carbon on the substrate may be regarded as a composite coating. Different gaseous species are also products of the reactions comprising the CVD process. Figure 2 shows variations in the calculated equilibrium molar concentrations of these various condensed and gaseous phases as a function of temperature (relevant to experimental MOCVD) in argon ambient at a total chamber pressure of 5 Torr. The calculations have been carried out assuming that one mole of the precursor is consumed. (If different amounts of precursors are considered, there will be a multiplication factor to the $y$-axis of figure 2, proportions of the resulting compounds remaining the same). Among the various compounds of manganese, only $\mathrm{MnO}$ is found to be thermodynamically favourable throughout the temperature range, accompanied by a large amount of carbon (3 moles of $\mathrm{C}$ are deposited with 1 mole of $\mathrm{MnO}$ ), irrespective of temperature. A similar set of calculations, carried out as a function of total pressure in the CVD chamber, keeping the temperature constant at $600^{\circ} \mathrm{C}$ and $700^{\circ} \mathrm{C}$, indicates that the carbon content in the deposit is independent of pressure.

3.1b In oxygen ambient: An important variable in thermodynamic calculations is the relative molar concentrations of the reactants, i.e. the reacting oxygen gas, and the metalorganic complex (precursor), in the present case, denoted by $F_{\text {oxy }} / F_{\text {pre }}$. While this molar ratio $F_{\text {oxy }} / F_{\text {pre }}$ may be varied over a wide range experimentally, there is an upper limit to the number of moles of oxygen that can be consumed by one mole of the precursor, i.e. when all the constituent atomic species are completely oxidized. Here, the limit is 12.5 , based on the assumption of complete oxidation of $\mathrm{Mn}$, $\mathrm{C}$, and $\mathrm{H}$ to $\mathrm{MnO}_{2}, \mathrm{CO}_{2}$ and $\mathrm{H}_{2} \mathrm{O}$, respectively. Any amount of oxygen above this limit does not affect the thermodynamic calculations (although, in the actual deposition process, this extra oxygen may change the hydrodynamics of the CVD system).

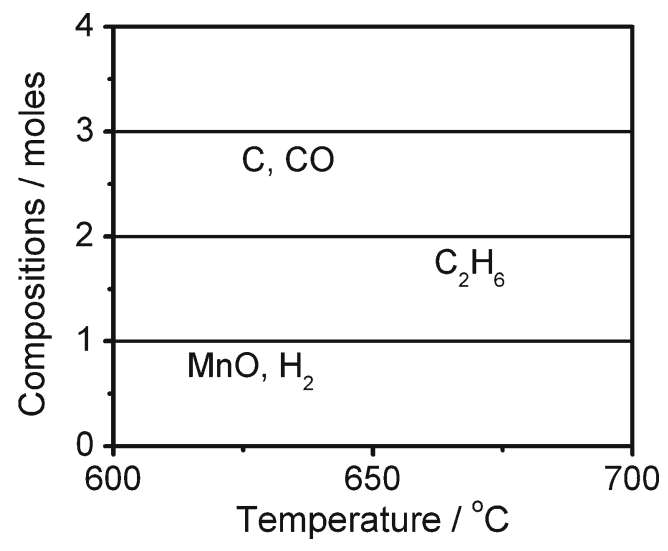

Figure 2. Calculated equilibrium molar concentrations of the various condensed and gaseous phases, as a function of temperature, for the CVD process carried out in inert (argon) ambient at a fixed total pressure (5 Torr). 
The range of $F_{\text {oxy }} / F_{\text {pre }}$ ratios used for the calculations is close to this upper limit, this being the range employed for the experimental CVD undertaken in this effort. When $F_{\text {oxy }} / F_{\text {pre }}$ is sufficiently high, higher oxides of manganese, i.e. $\mathrm{Mn}_{2} \mathrm{O}_{3}, \mathrm{Mn}_{3} \mathrm{O}_{4}$ and $\mathrm{MnO}_{2}$ are also formed. The thermodynamic analysis indicates that, under certain conditions, there are simultaneous depositions of ( $\mathrm{MnO}$ and $\mathrm{C}),(\mathrm{MnO}$ and $\left.\mathrm{Mn}_{3} \mathrm{O}_{4}\right),\left(\mathrm{Mn}_{3} \mathrm{O}_{4}\right.$ and $\left.\mathrm{Mn}_{2} \mathrm{O}_{3}\right)$, and $\left(\mathrm{Mn}_{2} \mathrm{O}_{3}\right.$ and $\left.\mathrm{MnO}_{2}\right)$. These are the condensed phase products of the CVD process. Correspondingly, $\mathrm{CO}, \mathrm{CO}_{2}$, and water vapour are expected in the gas phase, according to these calculations, signifying the oxidation of all the organic fragments into these vapours.

Figure 3 shows variations in the calculated equilibrium molar concentrations of the various condensed phases that are formed, as a function of $F_{\text {oxy }} / F_{\text {pre }}$, under fixed conditions of temperature and pressure, viz. $T_{\text {sub }}=700^{\circ} \mathrm{C}$ and $P=5$ Torr. Results of similar calculations, performed as a function of $T_{\text {sub }}$ are summarized by constructing a CVD phase-stability diagram to represent the formation of solid phases (figure 4). Thermodynamically allowed phases (pure and mixed) expected from MOCVD, as well as their "stability windows", appear naturally in the diagram, providing a guideline for the choice of experimental conditions required for the deposition of particular compositions.

It is interesting to note in these figures that pure $\mathrm{MnO}$ (or a composite of $\mathrm{MnO}$ and $\mathrm{C}$ at lower temperatures for lower values of $F_{\text {oxy }} / F_{\text {pre }}$ ) is the only thermodynamically allowed phase of manganese oxide in the major part of the phase diagram. The other oxides of manganese, and their composites, appear only at the higher values of $F_{\text {oxy }} / F_{\text {pre }}$, beyond which pure $\mathrm{MnO}_{2}$ is expected. No detectable regime was obtained for the deposition of pure $\mathrm{Mn}_{2} \mathrm{O}_{3}$ and pure $\mathrm{Mn}_{3} \mathrm{O}_{4}$. The boundary lines separating the regimes of pure $\mathrm{MnO}$, mixtures of $\mathrm{MnO}$ and $\mathrm{Mn}_{3} \mathrm{O}_{4}, \mathrm{Mn}_{3} \mathrm{O}_{4}$ and $\mathrm{Mn}_{2} \mathrm{O}_{3}, \mathrm{Mn}_{2} \mathrm{O}_{3}$ and $\mathrm{MnO}_{2}$,

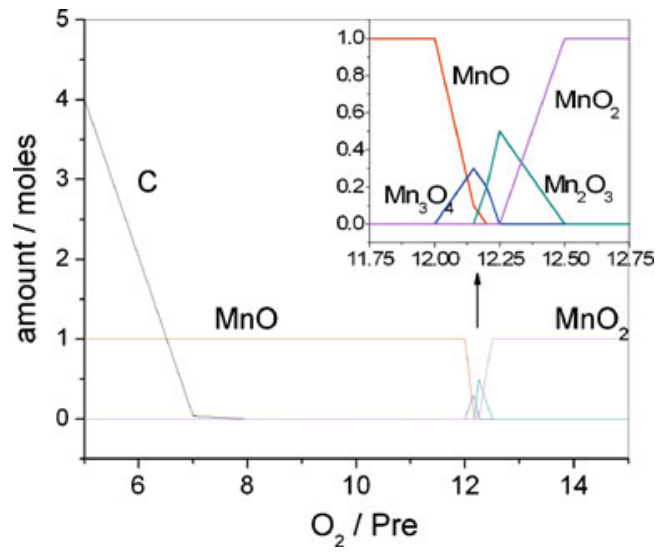

Figure 3. Calculated equilibrium molar concentrations of the various condensed phases formed, as a function of $F_{\text {oxy }} / F_{\text {pre }}$, for a CVD process carried out at $T_{\text {sub }}=650^{\circ} \mathrm{C}$, and a fixed pressure (5 Torr).

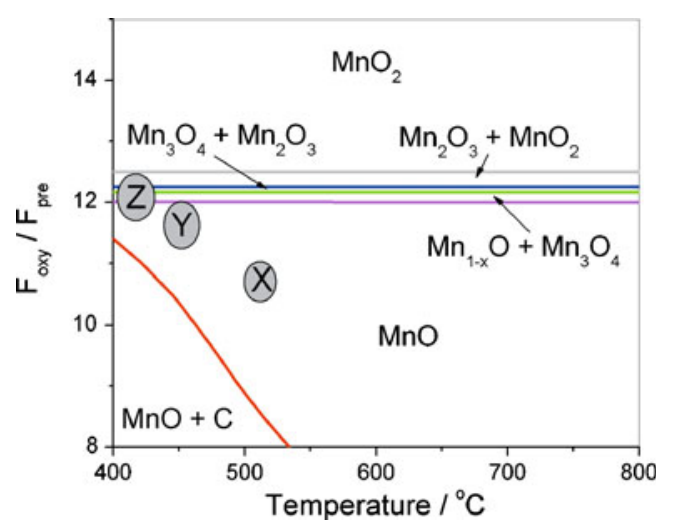

Figure 4. Calculated CVD phase stability diagram to represent the formation of solid phases for a CVD process conducted at a total pressure of 5 Torr. Experimentally deposited films: $\mathrm{MnO}(\mathrm{X})$, $\mathrm{MnO}+\mathrm{Mn}_{3} \mathrm{O}_{4}(\mathrm{Y}), \mathrm{Mn}_{3} \mathrm{O}_{4}+\mathrm{Mn}_{2} \mathrm{O}_{3}(\mathrm{Z}$ ) (in marking $\mathrm{X}, \mathrm{Y}, \mathrm{Z}$, average precursor flow rates were deduced from the precursor weight loss during the CVD process, which was accurately measured).

and pure $\mathrm{MnO}_{2}$, are found to be invariant with temperature. The compositions of the mixed-oxide deposits, resulting from the simultaneous depositions of different oxides, are also essentially independent of temperature. However, the $F_{\text {oxy }} / F_{\text {pre }}$ ratio required for the elimination of carbon from the deposit decreases as the temperature is increased. That is, the process window for the deposition of carbon-free pure $\mathrm{MnO}$ films becomes wider at higher deposition temperatures.

If a different volatile compound of manganese is used as the CVD precursor, a similar analysis would have to be carried out to construct the corresponding CVD phase stability diagrams for processes carried out at different ambients. Depending on the structure of this compound, the CVD conditions under given phases obtained may be quite different from those described here.

\subsection{Experimental deposition}

3.2a In argon ambient: Depositions carried out in argon ambient (and the absence of any flow of oxygen) took place in practice in the ambient of argon, and resulted in very black coatings on all the substrates employed. When the temperature of deposition exceeded $500^{\circ} \mathrm{C}$, the coatings on steel and alumina were found to adhere strongly to the substrate, as revealed by the adhesion tape peel test, regardless of the thickness of the coating. For example, depositions lasting 90 min resulted in coatings on steel and alumina measuring $\sim 3 \mu \mathrm{m}$ in thickness. However, coatings on $\mathrm{Si}(100)$ and $\mathrm{Si}(111)$ obtained from a 90-min deposition were found to buckle and peel off from the substrate.

$\mathrm{X}$-ray diffraction of the film on these various substrates showed them to be amorphous. Electron diffraction was therefore employed to probe the structure of the film further. The electron diffraction pattern of the film deposited in argon 


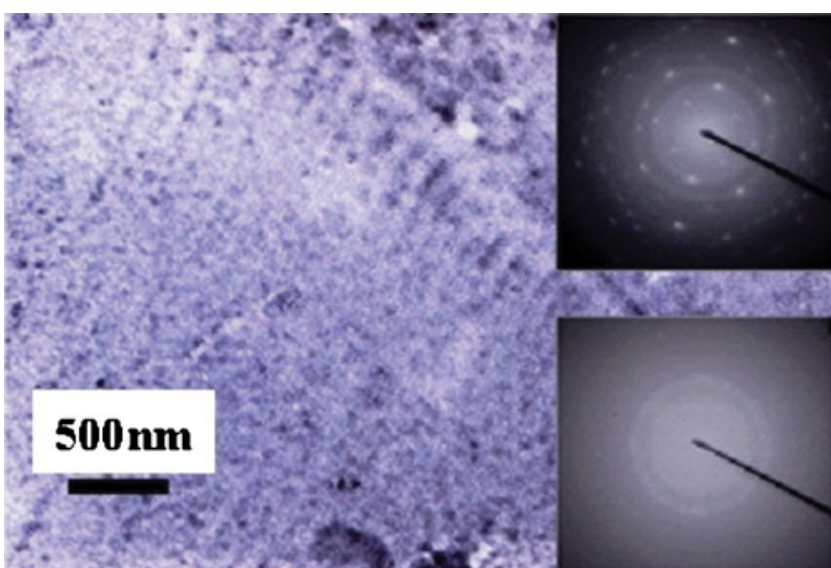

Figure 5. Bright field TEM image and SAED patterns of film grown on stainless steel in argon ambient at $T_{\text {sub }}=650^{\circ} \mathrm{C}$ and $P=$ 5 Torr. In an amorphous matrix of carbon, both nanocrystalline and amorphous $\mathrm{MnO}$ are embedded.

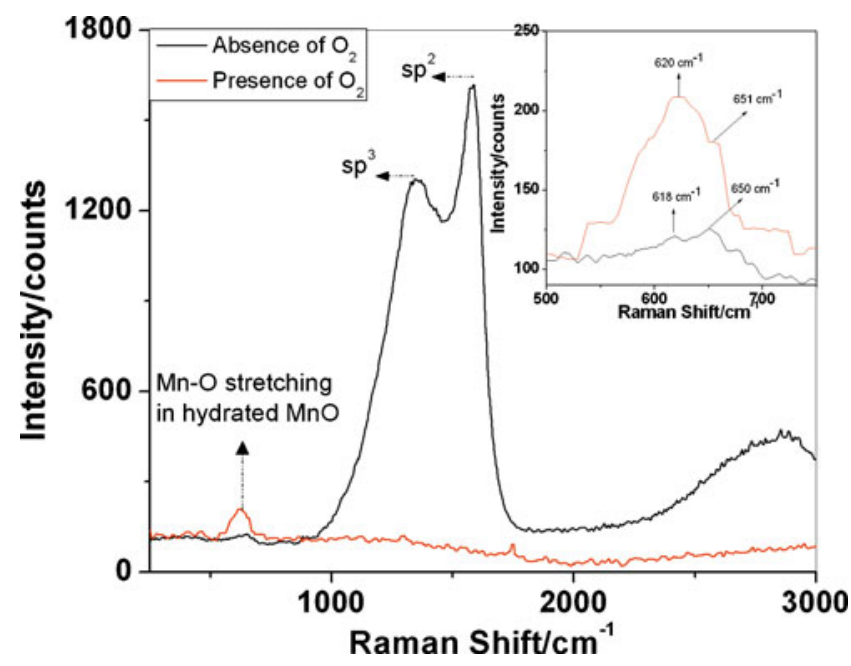

Figure 6. Raman spectra of films grown on stainless steel in (black) argon ambient $\left(T_{\text {sub }}=650^{\circ} \mathrm{C}\right.$ and $P=5$ Torr) and in (red) oxygen ambient $\left(T_{\text {sub }}=530^{\circ} \mathrm{C}, P=5\right.$ Torr and $1.5 \mathrm{sccm}$ oxygen flow).

ambient on SS 316 at $650^{\circ} \mathrm{C}$ is shown in figure 5, revealing that the film comprised of both amorphous and nanocrystalline $\mathrm{MnO}$. The bright field image confirms the largely amorphous nature of the coating. The blackness of the coatings indicated that they might be carbonaceous and, hence, they were examined by Raman spectroscopy. The Raman spectrum of a coating on SS 316 deposited at $650^{\circ} \mathrm{C}$ is shown in figure 6 , demonstrating convincingly the presence of both $s p^{2}$ and $s p^{3}$ elemental carbon in the film, the intensity of the spectrum implying that the proportion of carbon present is significant. Thus, the film consists of extremely fine $\mathrm{MnO}$ embedded in a carbonaceous matrix, thus forming a nanocomposite coating. The presence of carbon presumably limits the mobility of the nuclei of $\mathrm{MnO}$ considerably, despite the relatively high substrate temperature (Varade et al 2009). The formation of graphitic carbon at a temperature as low as $650^{\circ} \mathrm{C}$ is surprising (Kinoshita 1988), and probably is a result of the precursor being a metalorganic complex. This is consistent with the thermodynamic analysis of figure 2 , which shows that, in the absence of any oxygen, the solid deposit should comprise of carbon and $\mathrm{MnO}$ in a 3:1 molar proportion. This quantitative agreement validates the abbreviated initial list of chemical species used for thermodynamic analysis. In this way, the approach presented here promises to substitute for the elaborate and expensive proposition of a mass spectrometer downstream of the CVD chamber otherwise needed to investigate the gaseous products.

The microstructure of such a carbonaceous coating is further revealed by the scanning electron micrograph of the coating deposited on SS 316 at $650^{\circ} \mathrm{C}$ (figure 7). The structure is very intricate, featuring a cauliflower-like morphology, together with porosity characteristic of it. The extremely fine particle size that is evident from the micrograph, together with the cauliflower morphology, can be expected to result in a large specific surface area. Indeed, Brunauer-Emmett-Teller (BET) measurements confirm this (Varade et al 2009). The coating deposited on SS 316 is found to have a surface area of atleast $2000 \mathrm{~m}^{2} / \mathrm{g}$. The coatings prepared on $\mathrm{Si}(100)$ and ceramic alumina have a similar microstructure.

The chemical composition of the coating was examined in greater detail by X-ray photoelectron spectroscopy (XPS), carried out with $\mathrm{Al}-\mathrm{K}_{\alpha}$ radiation in an instrument with a resolution of $1 \mathrm{eV}$. For the film deposited at $650^{\circ} \mathrm{C}$ on SS 316, a quantitative estimation of the relative proportion of $\mathrm{MnO}$ and elemental carbon was made using the XPS data. The molar ratio of $\mathrm{MnO}$ to $\mathrm{C}$ is found to be 1:3.75 (Varade et al 2009), which is in close agreement with the results of the thermodynamic analysis (figure 2), despite the assumption made that equilibrium prevails during the CVD process. The quantitative XPS analysis also accounts for the blackness of the films

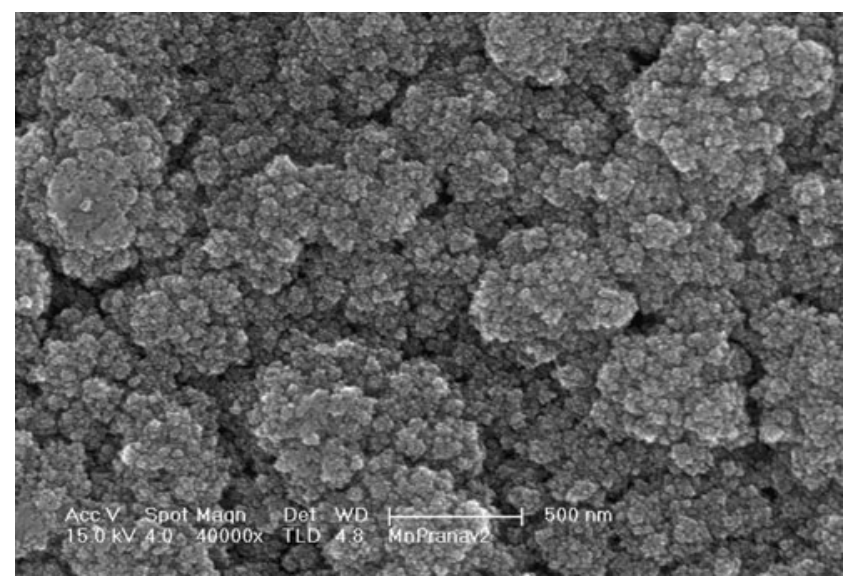

Figure 7. High-magnification SEM image of the film deposited on stainless steel in argon ambient at $T_{\text {sub }}=650^{\circ} \mathrm{C}$ and $P=5$ Torr, revealing the large surface area of the nanocomposite $\mathrm{MnO} / \mathrm{C}$ film. 
deposited in the absence in argon ambient, as does the strong signature of carbon in the Raman spectrum.

3.2b In oxygen ambient: Depositions were also carried out under different rates of oxygen flow, and thus at different values of the parameter $F_{\text {oxy }} / F_{\text {pre }}$, as well as at different temperatures (with argon as the carrier gas for the vapours of the manganese complex). The resulting films are different from those obtained in the absence of oxygen, the appearance being greenish, brownish, bluish, and even black, depending on the specific deposition conditions. In general, for a given duration of deposition, films deposited under oxygen flow were thinner than those deposited in argon ambient.

The films deposited in the presence of oxygen are also more crystalline than in the absence of oxygen, suggesting that the reduction or elimination of carbon in the deposit leads to a greater degree of mobility of the oxide growth species, and thus to increased crystallinity. When the rate of oxygen flow is very low, $1.5 \mathrm{sccm}$, and the substrate temperature is $550^{\circ} \mathrm{C}$, the film is greenish in appearance, and the XRD pattern identifies the materials deposited as $\mathrm{MnO}$ (figure 8a), with an average crystallite size of $\sim 30 \mathrm{~nm}$, as estimated by the Debye-Scherrer method. This contrasts with the barely crystalline $\mathrm{MnO}$ deposited in a carbon-rich matrix deposited in the absence of any oxygen flow. The presence of even a small proportion of oxygen in the growth ambient, at $530^{\circ} \mathrm{C}$, is sufficient to prevent any deposition of carbon, as revealed by Raman spectroscopy (figure 6). The absence of carbon is also evidenced in the sharply different morphology of the film. It is very fine-grained and smooth, the cauliflower structure and the associated large specific surface area being completely absent.

For other composite oxide films, the growth of one oxide affects growth of the other, reducing crystallinity, as revealed by the fine-grained smooth microstructure obtained by SEM.

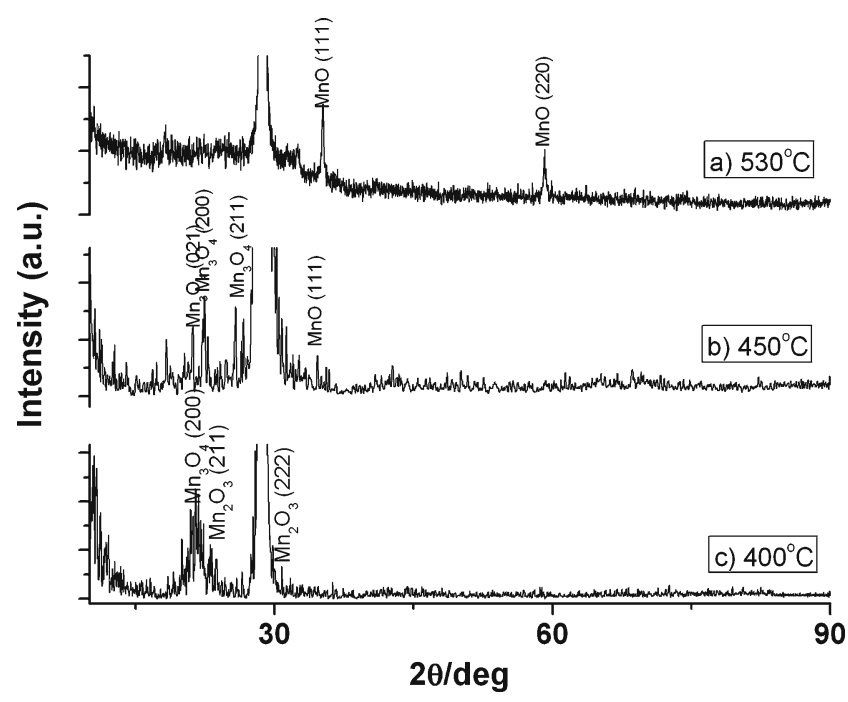

Figure 8. XRD pattern for films grown on $\mathrm{Si}(111)$ in oxygen ambient $(1.5 \mathrm{sccm}$ oxygen flow and $P=5$ Torr $)$.
These composite oxide films are characterized by XRD (figures $8 \mathrm{~b}$ and $\mathrm{c}$ ). These depositions carried out under oxygen flow can be "placed" on the CVD phase stability diagram, by computing the value of the parameter, $F_{\text {oxy }} / F_{\text {pre }}$, employed in each specific case. This is shown in figure 4, where the size of the circles is used to indicate the uncertainties implied by the assumptions made, viz. that equilibrium thermodynamics is valid, that the adsorption of both oxygen and metal precursor on the substrate is well behaved, and that the vapour of the metal precursor may be treated as a perfect gas (in computing $F_{\text {oxy }} / F_{\text {pre }}$ ). The regions in the phase stability diagram marked $\mathrm{X}, \mathrm{Y}$, and $\mathrm{Z}$ (figure 4) represent experimental data on the oxide-oxide composites actually realized. The molar flow rate ratios $F_{\text {oxy }} / F_{\text {pre }}$ were deduced from the precursor weight loss during the CVD process.

The conditions of deposition and the consequent compositions and microstructures are connected in another way. The absence of oxygen in the CVD chamber nevertheless results in the formation and deposition of $\mathrm{MnO}$, thanks to the direct $\mathrm{Mn}-\mathrm{O}$ bonds in the metalorganic precursor (figure 1). However, this occurs simultaneously with the formation and deposition of copious amounts of elemental carbon. The presence of carbon presumably limits the mobility of the nuclei of $\mathrm{MnO}$ considerably, despite the relatively high substrate temperature. This results in a film with largely amorphous or nanocrystalline $\mathrm{MnO}$ particles embedded in a carbonaceous matrix, providing the microstructure/morphology that has been described. However, in the presence of an adequate proportion of oxygen in the CVD chamber, the reactions favour the formation of various oxides of manganese, without any elemental carbon being simultaneously formed.

\section{Summary and conclusions}

Equilibrium thermodynamic modeling has been applied to the low-pressure MOCVD process conducted in inert and oxygen ambients, using manganese acetylacetonate as the precursor. A highly carbon-rich deposit of $\mathrm{MnO}$ is predicted by the analysis, at low pressure, over a range of temperatures. This is verified by experiment quantitatively, by conducting depositions in argon ambient, and measuring the carbon-to- $\mathrm{MnO}$ ratio in the resulting deposit. The carbonrich matrix leads to the formation of a $\mathrm{MnO} / \mathrm{C}$ nanocomposite with a large specific surface area. Depositions conducted in oxygen ambient substantially verify the predictions of the CVD phase stability diagram constructed from the thermodynamic analysis. Thus, the present work demonstrates that thermodynamic analysis can be employed to deduce process conditions experimentally required to obtain films of desired compositions, thus rendering MOCVD process development less empirical and more effective. The prospect of synthesizing films of unusual compositions with interesting microstructures makes such an effort worthwhile. 


\section{References}

Baum T H and Larson C E 1993 J. Mater. Sci. Lett. 140154

Devi A, Shivashankar S A and Samuelson A G 2002 J. Phys. IV 12(PRIV) 139

Dhar S, Dharmaprakash M S and Shivashankar S A 2008a Bull. Mater. Sci. 3167

Dhar S, Shalini K and Shivashankar S A 2008b Bull. Mater. Sci. 31 723

Eriksson G 1971 Acta Chem. Scand. 25651

Fredriksson E and Forsgren K 1995 Surf. Coat. Technol. 88255

Huang J L, Pan C H and Lii D F 1999 Surf. Coat. Technol. 122 166

Jang J H, Han S, Hyeon T and Oh S M 2003 J. Power Sources 123 79

Jang J H, Kato A, Machida K and Naoi K 2006 J. Electrochem. Soc. 153 A321

Jeong Y U and Manthiram A 2002 J. Electrochem. Soc. 149 A1419

Kang S Y, Choi K H, Lee S K, Hwang C S and Kim J H 2000 J. Electrochem. Soc. 1471161

Kim H and Popov B N 2002 J. Power Sources 10452

Kinoshita K 1988 Carbon - electrochemical and physicochemical properties (New York: John Wiley and Sons Inc.)
Lee H Y and Goodenough J B 1999 J. Solid State Chem. 144220

Lee H Y, Kim S W and Lee H Y 2001 Electrochem. Solid State Lett. 4 A19

Mane A U and Shivashankar S A 2003 J. Cryst. Growth 254368 Mukhopadhyay S, Shalini K, Lakshmi R, Devi A and Shivashankar S A 2002a Surf. Coat. Technol. 150205

Mukhopadhyay S, Shalini K, Devi A and Shivashankar S A 2002b Bull. Mater. Sci. 25391

Pang S C, Anderson M A and Chapman T W 2000 J. Electrochem. Soc. 147444

Park J H, Ko J M and Park O O 2003 J. Electrochem. Soc. 150864

Sarin V K 1995 Surf. Coat. Technol. 7323

Singh M P, Raghavan G, Tyagi A K and Shivashankar S A 2002 Bull. Mater. Sci. 25163

Stringfellow G B 1989 Organometallic vapour-phase epitaxytheory and practice (New York: Academic Press)

Varade A, Shivashankar S A, Dhar S and Sampath S 2009 WIPO Patent Publication no - WO2009022351 (http://v3.espacenet. com/publicationDetails/biblio?CC $=$ WO \&NR $=2009022351 \mathrm{~A} 1 \&$ $\mathrm{KC}=\mathrm{A} 1 \& \mathrm{FT}=\mathrm{D} \&$ date $=20090219 \& \mathrm{DB}=\&$ locale $=$ )

Vossen J L and Kern W 1991 Thin film processes II (New York: Academic Press) Ch. III-1, III-2

Zheng Z P and Jow T R 1995 J. Electrochem. Soc. 142 L6 